\title{
DEVELOPING EFFICIENT FOREIGN LANGUAGE CLASSROOM ENVIRONMENTS FOR OLDER ADULT LEARNERS
}

\author{
AgATA SŁOWIK-KROGULEC \\ Institute of English Studies, University of Wrocław \\ ul. Kuźnicza 22, Wrocław, Poland \\ E-mail address: agata.slowik@uwr.edu.pl \\ ORCID: 0000-0002-5530-3880
}

\begin{abstract}
Aim. The aim of the research is to present which elements related to teaching English to older adult learners have the greatest influence on creating a propitious and friendly learning environment. In order to achieve this firstly, I wish to present older adults' observations regarding problems encountered in the classroom environment related to the lack of teaching materials, mixed age and ability groups or being discriminated against by fellow students and teachers. Secondly, I would like to propose some solutions to improve the efficiency of both students and teachers in the classroom environment.

Methods. The subjects of the study were 40 older adult learners of English who attended the classes at the University of the Third Age in Wrocław. In the study, the participants were asked to choose the answers which, according to them, have the greatest influence on their learning the foreign language in later life. The participants also wrote additional comments that explained their choices. The analysis was qualitative in nature.

Results. The analysis shows that teachers $(n=35)$ and teaching materials $(n=31)$ are considered to be the two most important factors in learning a language in later life. The third most vital factor in creating a good classroom environment is related to other students $(\mathrm{n}=17)$. The subjects' comments, however, point to numerous problems encountered in the aforementioned areas that affect the process of foreign language learning in later life.

Conclusions. Older adult learners' needs, abilities and learning preferences should be taken into account while designing language courses as, according to the subjects of the study, at present, it is not the case. Moreover, the teachers' awareness of the age-related changes that make certain tasks difficult and the learning environment unnecessarily hostile should be raised.

Key words: University of the Third Age, U3A, older adults, classroom environment, foreign language geragogy
\end{abstract}




\section{FOREIGN LANGUAGE CLASSROOM ENVIRONMENT}

A lot has been written to date about creating a foreign language learning adults' needs and cognitive abilities have been neglected in the discussion of ensuring a pleasant and stimulating physical, psychological and instructional environment. Bernhard Schmidt-Hertha, Sabina Jelenc Krašovec and Marvin Formosa (2014), the editors of Learning Across Generations in Europe: Contemporary Issues in Older Adult Education, enumerate factors that should be taken into consideration in the discussion of Foreign Language Geragogy. Firstly, the authors point out that, "generational identities and age-related needs can be forms of diversity that adult education programs have to address" but they also note that these "differences between age-groups and generations can be seen as central catalyst for educational processes, when confrontation and mutual participation of people with different experiences and different living conditions becomes the centre of learning" (p. 3). Teachers need to be aware of how to design their courses in such a way that they can make use of their learners' heterogeneity and treat it as an inspiration and means of improving their skills rather than as an obstacle in teaching (see Franz, 2010). However, B. Schmidt-Hertha, S. Krašovec and M. Formosa (2014) also note that it is likely that some topics could be more suitable for groups of homogenous learners and would answer their learning needs and preferences. Lastly, the authors note that each group of learners belongs to a community or a larger social group and it is therefore crucial that their learning preferences are taken into account so that they can relate to possible problems and obstacles that might be present in these various social situations. Hence, teachers and educators of older adults need to be aware of the significance of giving "social meaning to learning and educational activities and therefore include all the participants in planning educational goals and their achievement" (pp. 3-4).

The first attempts aimed at forming an educational theory that would address older adults' special educational needs and learning preferences were made as early as in 1978, when Jacques Lebel argued that only a separate theory of teaching older adults, namely geragogy, "is appropriate to address and take into account the special learning characteristics, needs, motivations and barriers to participation that are particular to older people whose learning at the final stage of life is largely self-initiated and voluntary" (Tam, 2014, p. 5). In other words, the highly heterogeneous character of later life and the already mentioned diversity of accumulated knowledge, also the one which is connected to learning, single the group out and make planning the curricula and lessons more challenging than it is often believed. The changes taking place in later life are complex and although they can differ markedly within each group of learners, they are also universal for all older people. As Maureen Tam (2014) points out, "given the changing circumstances and transitions accompanying the advancement of age, older learners are characterised by the specific needs and purposes of pursuing continued learning that are unique 
to them as a distinct group of learners from their younger peers. By the same token, elder learners will experience learning difficulties and barriers that are unique to their changing life circumstances and experiences associated with older adulthood" (p. 3). According to the author, the problems that older learners face in the classroom can therefore be divided into three main categories: dispositional, situational and institutional. The first issues are of psychological nature and are associated with one's previous negative learning experiences or the feeling of discomfort when studying in the same group with much younger learners. The second category is connected with possible ongoing problems such as failing health, an illness of a spouse or their death, as well as the lack of finances. Finally, there is the institutional barrier, which is linked to various actions carried out in this case by, for instance, colleges, universities, and language schools, which, although often unconsciously, exclude older adults from taking part in the process of learning. These, according to M. Tam (2014) include the issues with "insufficient choice of courses, poor scheduling of classes, admission and other administration problems" (p. 3; see also Cross, 1981).

In addition, older adults experience the so-called "paradox of time" (Russell, 2011). The problem is twofold: on the one hand, following the retirement older adults have a lot of free time, which they can spend in any way they wish, but on the other hand, their advanced calendar makes them choose their preferred activities more carefully. It also has an influence on the choice of classes older learners attend - provided the classes are pleasant and motivating, they will continue their education. But, if the classes are boring, too difficult and overly challenging, and the teacher is highly ambitious and, therefore, perhaps unreasonably demanding, the students will give up continuing their education. It should be noted that, "[t]he concept of time in the final stage of life may differ qualitatively from that of time in mid-life, causing [older adults] to engage in learning for distinct reasons and needs as well as to approach and pursue learning in ways different from their younger counterparts" (Tam, 2014, p. 4). With that in mind, teachers should make sure that the classroom environment they create answers the needs of older students, who volunteer to be there both to learn and to enjoy, perhaps in equal measure.

The last period of human ontogeny is often seen in terms of its socio-cultural qualities, at the same time disregarding or perhaps failing to emphasise its universal and natural character (Findsen, \& Formosa, 2011, p. 105). Moreover, although it is widely recognised that the previous experiences and present biological, cognitive, neurocognitive, psychological and sociological changes taking place in later life differ markedly from the ones experienced by younger adults, this issue seems to be not given enough attention while planning language courses. The insufficient awareness on behalf of older adults' teachers and educators is often far-reaching also in the case of language courses. It is, therefore, essential to take older adult learners' needs, abilities and learning preferences into account while planning out curricula, course books, additional materials, or designing university courses for pre-service language teachers. 
Brian Findsen \& Marvin Formosa (2011) also enumerate problems that learners who continue their education in later life might face and claim that, "older adults returning to the classroom generally face a challenge to their independence and control" (p. 107). The longer break in formal educational development leads to an increasing feeling of insecurity. Also, the mentor-student relationship and the reversal of life roles can cause the feeling of anxiety and inferiority. As a result, being in the position of a student may prove to be difficult especially when the teacher is often much younger. Therefore, according to the authors, it is vital for the educator to encourage the learners to take an active part in the process of learning. The curriculum designed for this age group should, thus, be carefully thought-through in order to reflect the real needs of the students and to truly benefit the course participants. This might be done by either tailoring the curriculum to particular groups of learners or by trying to leave space for involving the students to share their vast knowledge and experiences while offering guidance and necessary support. According to the authors, especially in the past decade, peer-teaching has become a subject of scientific research and an increasingly popular teaching strategy offered to older learners (see also Choi, 2009; Erickson, 2009). As a result, it is thought to be crucial for language teachers to allow their learners to take an active part in the process of learning and to enable them to contribute in a meaningful way by sharing their own experiences. In a similar vein, following the statement by Malcolm S. Knowles (1990), Ernest Chui and Xinyi Zhao (2016) noted as follows: "Elder learning programme providers should recognise the specific learning styles of older adults. Elder learning, as part and parcel of adult learning, is basically a cooperative venture in informal, non-authoritarian learning environment. The main objective for adult learning is to discover the meaning of experience, and is therefore 'life-centred'; that is, targeted toward enhancing people in their functioning in daily living, instead of merely acquiring a particular academic qualification. Thus, the appropriate units for organising adult learning are life situations but not subjects" (p. 176). This means that the teachers should develop a sensitive, flexible and open-minded approach to teaching fourth-age learners that will help to concentrate on individual differences, needs and various experiences. Moreover, the motivation of each learner to study the language should be clarified at the beginning of each course so that the speed and content of each lesson will include materials that are useful to the learners. In other words, the studies show that older learners hardly ever (if at all) learn the language in order to get a certificate (except for rare cases in which individuals take exams to prove themselves or their children and/or grandchildren that they are still capable of passing tests or being successful language learners). Instead, there are many other much more common reasons, such as: an ability to communicate with their English-speaking friends and family (especially children's spouses and grandchildren born abroad), to travel, to browse the internet, watch films, read books, understand the world around them, or simply to use English 
classes as means of socialising and spending time with others in a meaningful way that involves exercising their brains. It is, therefore, worth arguing that nowadays the role of the Universities of the Third Age should be not only to ensure high standard of education but also to create a propitious, friendly and motivating learning environment for older adult learners, in which their learning needs, preferences and cognitive abilities will be taken into account.

\section{RESEARCH}

The study presented in this paper was related to the broadly understood classroom environment and included one open-ended question discussed during the interview with the learners, in which the students were asked to identify this element (or elements) related to learning a foreign language which, in their opinion, has the most influence on their language development. The options included the following categories: teacher, other students, teaching materials, classroom layout, and other.

The subjects comprised the group of 40 older adult learners at the age of $60+$, who attended the classes at the University of the Third Age in Wrocław from October 2016 to February 2017.

The research was based on one question with a choice of "yes" and "no", which was followed by students' own comments, therefore the analysis was qualitative and descriptive in nature.

The question presented to the respondents was phrased as follows: Which of the following has, in your opinion, an influence on your language development and why?

- teacher

- other students

- teaching materials

- classroom layout

- other (please specify)

Regarding the classroom environment, the subjects $(n=40)$ gave a total of 129 answers, in which the majority of students $(n=35)$ pointed to teachers as playing the most important role in creating a propitious environment for students' growth and teaching materials $(n=31)$ as the second most important aspect related to learning a language. Other students $(n=17)$ and classroom layout $(n=9)$ were of secondary importance. The classroom layout had an almost equal number of responses in favour of its influence $(n=9)$ and against it $(n=8)$ (see Table 1 below). Every student who took part in the survey marked one or more answers but not all of the participants wrote their additional observations. 
Table 1.

Research results

\begin{tabular}{lcccccc}
\hline & Teachers & $\begin{array}{c}\text { Other } \\
\text { Students }\end{array}$ & $\begin{array}{c}\text { Teaching } \\
\text { Materials }\end{array}$ & $\begin{array}{c}\text { Classroom } \\
\text { Layout }\end{array}$ & Other & Total \\
\hline Yes & 35 & 17 & 31 & 9 & 9 & 101 \\
No & 3 & 9 & 5 & 8 & 3 & 28 \\
Total & 38 & 26 & 36 & 17 & 12 & $\mathbf{1 2 9}$ \\
\hline
\end{tabular}

Source: Own research.

\section{TEACHERS}

Teachers were chosen as the major factor that influences the learners' language development. Whether the learners had classes with native speakers of English or with Polish teachers all but one observation highlighted similar problems in understanding due to the teachers' pace of speech (S2: “The native speakers speak too fast, they should remember that we are older and need more time to understand, sometimes they should repeat what they say. I would like them to speak more slowly and clearly"; S37: "They are very nice and helpful, but tell them that they speak too fast, we can't understand and then they are irritated that they have to repeat everything"; S14: "He [The teacher] is extremely nice but he constantly forgets to slow down when he speaks, I think he is sometimes irritated that we don't understand what he says, and I know that he can find classes with us quite frustrating at times"; S36: "They [the teachers] think that everyone who learns English can talk that fast, I can't even listen that fast" (sic.); S18: "English is a beautiful language, I like the way it sounds, so it's like listening to a song, you don't always understand every word, right?"). One learner also noted that the teacher does not show enough care to bring materials that would have the appropriate size for the learners (S1: She [the teacher] never remembers to make larger copies, it's an extra problem for her").

\section{TEACHING MATERIALS}

The participants of the study decided that teaching materials are the second most important aspect which has an impact on their learning. The students' answers could be divided into four main categories: course book layout and topics, recordings, and intercultural communicative competence. Older adults mentioned that the course books which are available for them and which they use during English classes do not meet their expectations because they have too many pictures and additional information that serves opposite purpose to the one which is unusually intended, i.e. to stimulate the students, to activate their schemata and to look more appealing (S31: "There is too much happening on these pages, I find it difficult to focus"; S35: "There is not enough place to write the answers, and I don't know where to look"). Another learner noted, 
in a similar vein, that the books do not take into account the learners' possible visual impairments (S3: "The font in the course books is too small").

The second group of observations is connected with the topics offered in the course books for adults, which are available on the market and are aimed at younger, professionally active members of society (S5: "I'm not interested in reading about teenage pop singers"; S16: "I'm unlikely to "change my profession' as I'm retired so what's the point of having the whole unit about it. It's also quite depressing. I'm sure my colleagues would say the same"; S34: "I can't relate to these texts [in the course book], it's really frustrating, they are made for the young, not for us, sometimes I feel that I should give it all up, but my wife says I have to learn for my grandchildren, so here I am, maybe we will have more topics in common after that"). One other learner complained that there are too many grammar tasks, which are not his/her learning priority (S30: “Do I really need to do all of these grammar exercises, I only want to communicate, is it bad if I make mistakes?").

Thirdly, the learners reported their problems with understanding of the recordings which are a part of each language course book due to their attempt to be as authentic as possible and to imitate real-life situations, hence often including background noise (e.g. loud noise at the train station drowning out the information about arrivals). One student was aware of the aim of these additional sounds but highlighted that they make the announcement incomprehensible; S35: "I hate that there is always some noise in the background [in the recording], I know it's more authentic then but what's the point if I can't understand anything they say"). In addition, older adults made some comments related to listening exercises used in the classroom in which it was clear that they were aware of some difficulties, even though they were not able to name or sometimes even describe them. The participants pointed out that the authentic speech with elements of, e.g., connected speech and linking can also make it hard to listen for specific information (S17: "The utterances are incomprehensible, they sound like one long word, I can't understand it because I don't know where the words begin and end"; S2: "I can't hear the disappearing ends of words"; S8: "Sometimes some words sound the same as others, and yet they are often pronounced in a different way or they are different words at all, when I look them up in the dictionary. Also, the recordings are far too fast to comprehend"). Another learner complained about the quality of the equipment and recorded information and claimed that they are not loud enough (S40: “The recordings are too quiet, I can't hear properly, I have to sit closer to the CD player"). Finally, one participant pointed out that the speed of the recordings was not adapted to older adult learners' abilities, which made it hard to understand the message and expressed his/her belief that the teachers use these recordings as fillers during the lesson (S28: "I' $m$ not sure what is the point of these exercises, we can never understand what they [people in the recordings] are talking about, it's a waste of our time, even when I see the tapescript I can't follow the text, I can't read that fast in the foreign language so what's the point. It seems that teachers like it 
because they don't need to do anything when we're listening to these long recordings").

Moreover, one participant observed that people of many nationalities are recorded and they have accents which pose an additional difficulty in terms of comprehension (S3: "Nowadays the people in the recordings have very strange accents, I think they [course book authors] do that on purpose to make it more difficult, I don't see the point - why can't we listen to 'normal' English?"). One other learner noted that he/she finds it not easy to follow the given tasks while listening to the recording (S5: "When we listen there is no time to read the instructions and write the answers"). However, there were also positive comments expressing the belief that practice makes perfect and each exercise can prove to be useful in developing one's listening comprehension (S16: "I appreciate these listening exercises, I'm sure that I can learn something new even when I'm just listening to the sound of an authentic speech"; S38: "The more I listen to the radio the better I'll get at listening in the classroom").

The final group of observations is associated with teaching the intercultural communicative competence as, for instance, three of the respondents seem to be aware of its value as part of the process of learning a language (S34: "I need to know how to behave and what to say when I'm travelling so that I don't commit a blunder"; S11: "Trying to talk to my friends in English [during the classes] will finally help me understand the native speakers, but will I know what to say?"; S22: "The greatest thing we've learnt this year was that we shouldn't complain when someone asks us "How are you?" - I would never have guessed it myself"). Two other participants appreciated classes devoted to ICC as they found them interesting (S1: "Recently when I watched a film I saw some of the places in London that we talked about during one of our classes, it felt really good, one day I will go there myself"; S27: "I love learning about English-speaking culture, it's so fascinating, we could definitely do that more often").

\section{OTHER STUDENTS}

The comments related to other students can be divided into two groups. Some remarks are very positive (S16: "I love these classes, this is my reason to go out, I made many friends, even with the younger classmates"; S31: "Other students are very helpful, I feel younger when I work with them"; S28: "Other students are definitely very good listeners even if they only pretend to be interested in my stories), but there were also more bitter observations, which suggest that there is still a lot to learn in order to fight one's prejudices and stereotypes (S35: "Our younger colleagues could be a bit more patient, they can never wait for me to finish my sentence, when they are my age it will be the same for them"; S40: "Patience, patience, patience and more open-mindedness"; S11: "Other students also get irritated when I ask them or the teacher to repeat certain parts, maybe I do that too often"). 


\section{CLASSROOM LAYOUT}

Classroom layout, although chosen to have the least influence on the process of learning was commented on 8 times and all of the opinions tackled different problems. Two learners mentioned visual and hearing impairments that make it hard for them to see and hear properly, which is the fault of a too large classroom in which not all of the learners have comfortable position (S24: "I sit too far, I can't see properly what's written on the whiteboard"; S14: I need to sit closer to the teacher in order to hear better"). Two other students, on the other hand, had a problem with a too small classroom in which one participant found it difficult to move around (S5: "I don't like it when the teacher tells us to change pairs or groups or to move around the classroom, there's not enough space and I sometimes refuse to get up so many times"), while the other pointed out that there was not enough space for each learner (S10: "The tables are too small and uncomfortable").

Three participants commented on the use of technology but their answers differed - one learner was very pleased to use the OHP (S7: "they [the teachers] use these projectors, I like that very much, it's interesting"), one student, after the initial anxiety, learnt to enjoy using computers while learning English (S9: "We worked in a computer room and posted our texts online, it was stressful but really nice that others could read what we've done"), and one older adult complained about such modern methods (S12: "There's too much technology used"). Finally, the last participant paid attention to high standards of cleanliness during his/her English classes (S24: "It's a nice and clean classroom").

\section{OTHER}

Among other comments one learner noted that the amount and level of difficulty of tests which they have to write is not appropriate for this age group (S1: "There are too many tests and they are too difficult, the tests should be adapted to our abilities. It's extremely stressful. Bad results are also very discouraging"). Another person highlighted the problem related to the use of the learners' mother tongue during the lesson, which is already discussed in the earlier section (S5: “Using Polish is often frowned upon. I'm Polish and I would feel better if I could speak the language if I find it helpful. I don't understand the problem"). The issue of age discrimination was also raised by one student who claimed that "Younger learners are favoured over us when it comes to their needs, it would be nice if we could be given similar learning opportunities" (S13). The last two comments are related to the classroom practice and the teachers' understanding of their students' preferences. The learners claim that they come to the classes to socialise as well as to study and therefore they do not need to cover so much material (S8: "We want to have more time for socialising in the classroom, not only grammar, vocabulary, listening, tests... We had that when we were at school, now we 
want to enjoy ourselves and the process of learning"; S20: "Why do we have to hurry with the book? We are retired, we have time, we can slow down a bit!").

\section{CONCLUSIONS}

The research to date shows that there are many differences between older adult learners regarding their perception of a friendly and motivational classroom environment in teaching English, however, there are also many important similarities, which should be stressed out and taken into account while designing courses for this age group.

In order to create more encouraging learning conditions, teachers should create a comfortable and non-threatening learning environment, establish a good rapport with the learners, develop the quality of openness to others, go at an appropriate pace for the learners and involve their older adult learners in designing the lessons. Moreover, they should adapt their materials so that they are suitable for older adult learners' cognitive abilities, adjust the classroom layout, allow for the use of students' L1 and be more open to the use of translation as means of teaching the language. Older adult educators should also realise that their learners are not only interested in developing their language skills but also in the opportunity to engage in stimulating mental activities and to socialise with their peers. There is also a need for creating teaching materials which would answer the needs of the learners and which would take into account their interests and reasons for learning the language and would inspire them to continue their lifelong education in later life. Thus far, the materials used in teaching English to older adult learners often do not meet the needs, abilities and learning expectations of the group and can be biased and based on stereotypes of old age rather than on actual research.

Finally, there is still a lack of theoretical and often also practical knowledge of which teaching and assessment techniques could facilitate the process of learning of older adults. Older adult educators who are preparing language programmes for this age group should recognise the specific learning styles of older adults. Moreover, with the growing percentage of older adult learners in our society, there should be some place in the curriculum designed for pre-service teachers (but also to experienced teachers who have no previous experience in teaching this age group, or who would like to learn more about Foreign Language Geragogy ${ }^{1}$ ) devoted to teaching older adult learners so that they can later answer the needs and expectation of this age group. Older people could also become more involved in the maintenance of their past skills and interests and developing new ones by taking an active part in designing the programmes and sharing their experiences during lessons (also as a form of peer-teaching). The system of evaluation of older adult learners

1 Gómez (2016) introduced the term Critical Foreign Language Geragogy, here it is used in a changed version. 
should be rethought so that it is less stressful and more student-friendly and the content of the lesson should be given more attention so that it answers the needs of the learners and they can relate to it. Along similar lines, the workload should be adjusted so that it does not put any additional strain on the learners.

Hence, it is perhaps worth recalling "the objectives of the first universities for the third age, similar to the ones in Toulouse," which according to B. Findsen and M. Formosa (2016), "were to provide the older students with a culturally motivating learning environment, with discussions among peers, civic consciousness, an occupation for their free time and the development of social networks. They put special emphasis on the rethinking of stereotypes and prejudices related to ageing" (p. 64). Such attitude to teaching older adults could have a wider application in the case of, for instance, language courses. The teachers should, thus, be made aware, or at least reminded, that their senior students are there not only to learn a new language but also to learn more about the English-speaking countries, their culture and habits, to meet new people and have a motivating reason to leave home every week, as well as to attend the classes which are inspiring and interesting but also tailored to their needs and learning abilities. This knowledge together with a more relaxed and understanding attitude to language teaching could also help to avoid the inhibition of some of the learners to follow their teacher, caused by, for instance, various subjective theories and earlier learning habits, which are different from the teacher's own expectations. In addition, although seemingly very obvious, it should be stressed out that teachers need to be there for their learners and, if necessary, change their teaching style, adjust the materials including the font size, the volume of the speakers or the classroom layout. Sometimes it is also required to leave behind one's personal beliefs or knowledge of how languages should be taught and become more straightforward and explicit in presenting it by taking into account students' possible aural, visual, motor and cognitive decline as well as their learning preferences.

The abovementioned research results, as well as conclusions of the study, are hoped to enrich the already existing knowledge of geragogy and second language learning and teaching, which continue to develop in Poland as two separate disciplines, and to raise teachers' awareness of special educational needs of older adult foreign language learners.

\section{REFERENCES}

1. Choi, I. (2009). The meaning of older adults' peer teaching: A phenomenological study. Educational Gerontology, 35(9), 831-852.

2. Chui, E., \& Zhao, X. (2015). Honk Kong. In: B. Findsen, \& M. Formosa (Eds.), International perspectives on older adult education: Research, policies and practice (pp. 99-110). New York, NY: Springer Berlin Heidelberg.

3. Cross, P. (1981). Adults as learners. San Francisco, CA: Jossey-Bass.

4. Erickson, D. (2009). Learning in retirement peer instructors: In over their heads or swimming comfortably. Educational Gerontology, 35(5), 393-408. 
5. Findsen, B., \& Formosa, M. (2011). Lifelong learning in later life: A handbook on older adult learning. Rotterdam: Sense Publ.

6. Findsen, B., \& Formosa, M. (Eds.). (2016). International perspectives on older adult education: Research, policies and practice. New York, NY: Springer Berlin Heidelberg.

7. Franz, J. (2010). Social cohesion and intergenerational learning arrangements. Retrieved from www.bpb.de/files/XR5A1H.pdf on 15.04.17.

8. Gómez, D. R. (2016). Language teaching and the older adult: the significance of experience. Bristol Buffalo Toronto: Multilingual Matters.

9. Knowles, M. S. (1990). Adult learner: A neglected species. Houston: Gulf Publishing.

10. Lebel, J. (1978). Beyond andragogy to geragogy. Lifelong Learning: The Adult Years, 1(9), 16-18.

11. Russell, H. (2011). Time and meaning in later-life learning. Australian Journal of Adult Learning, $5,547-565$.

12. Schmidt-Hertha, B., Kras ovec, S. J., \& Formosa, M. (Eds.). (2014). Learning across generations in Europe: contemporary issues in older adult education. Rotterdam Boston, Taipei: Sense Publishers.

13. Tam, M. (2014). A distinctive theory of teaching and learning for older learners: why and why not? International Journal of Lifelong Education. Retrieved from http:/ / dx.doi.org/10.1080/0260 1370.2014.972998 on 02.11.2017. 